\title{
Distribution modeling, soil properties, and variation in essential oils chemical composition of Rhanterium adpressum Coss. \& Dur.
}

${ }^{1}$ Laboratoire des Sciences Fondamentales à l'Université Amar TELIDJI de Laghouat, Route de Ghardaïa BP37G (03000), Laghouat, Algérie

Corresponding author E-mail:d.tahri@laghuniv. $d z$

\author{
Djilali Tahri $^{*}$, Fatiha Elhouiti ${ }^{1}$, Mohamed Ouinten ${ }^{1}$, Mohamed Yousfi ${ }^{1}$
}

\begin{abstract}
Modeling the distribution of Rhanterium adpressum, an endemic species from southwestern Algeria, and the interactions of soil's chemical properties with the variability of chemical composition of its essential oils makes the objective of this study. Obtained MaxEnt model $(A U C=0.98)$ showed that the general distribution of genus Rhanterium established mainly by the contribution of eight bioclimatic variables derived from temperature and precipitation (90.5\%). Projection of the model in future conditions until 2070 reveals that the habitats of this species will be very affected by climate changes. The analysis of 9 soil samples shows a sandy (77-96\%), alkaline, and calcareous character with an electrical conductivity between 0.2 and $1.8 \mathrm{dS} / \mathrm{m}$ at $20^{\circ} \mathrm{C}$. The chemical composition of terpenoids families during a period of 5 months was dominated by monoterpene hydrocarbons (70-90\%) followed by oxygen monoterpenes (4.5-9.2\%), hydrocarbon sesquiterpenes (1.6-9.9\%), and oxygenated sesquiterpenes (4.3-7.2\%). The variation of this composition in relation with phenological cycle and physicochemical properties of the soil was discussed.
\end{abstract}

KEYWORDS

Rhanterium adpressum, species distribution modeling, climate changes, soil properties, essential oils

(c))BY-NC-ND $\odot 2019$ Djilali Tahri et al.

This is an open access article distributed under the Creative Commons Attribution-NonCommercial-NoDerivs license

Modeling habitat suitability and species distribution in ecological sciences has created new perspectives for studies of the behavior of fauna and flora interacting with different environmental factors and conditions. Field observations, historical records, specimens from museums, and reliable observations recorded by amateurs with the emergence of "Citizen-Scientist" were the sources of data for these modeled investigations (Guisan et al., 2017). For this purpose, several computing platforms have been developed to generate robust and presentational models (Phillips et al., 2006; Leroy et al., 2016; Golding et al., 2018).

Generally in species distribution models, variables such as temperature, precipitation, their derivatives, and altitude are used to predict suitable habitat for species whether in the past or in current or future conditions and between the effective niches and real niches, differences can arise between generated models and actual dynamics for a particular popula- tion. One of the major factors influencing these differences is the physicochemical composition of soils, especially in arid environments where plants face various types of stresses affecting their distribution, morphology, and biological functioning (Hageer et al., 2017; Buri et al., 2017).

Many studies have focused on the aspects of the effect of constituents of edaphic factor on plant growth and chemical composition of different metabolites of interest. Essential oils have been shown to be affected by all these changes either by a high production of a family of terpenes or by variation in elemental components, characterizing one of the chemical responses to surrounding conditions.

Rhanterium adpressum Coss. \& Dur., a shrub of Inuleae tribe (Asteraceae) distributed in arid and hyperarid environments of Northwest Africa is the subject of this study with a maximum entropy modeling of its potential distribution in current and future climatic conditions; according to Representative Concentration Pathway (RCP) scenarios, properties of soil 
and variation in the chemical composition of essential oils have been interpreted and their relation has been discussed in the light of the other studies.

\section{MATERIALS AND METHODS}

\subsection{Plants samples and extraction of essential oils}

Aerial parts of $R$. adpressum were harvested for 5 successive months (November-March) from three different sites in southern Algeria. Coordinates, altitudes, and climatic character of these sites are presented in Figure 1. These sites are in a region of hyperarid climate characterized by a thermal amplitude of up to $38.6^{\circ} \mathrm{C}$ and an annual precipitation about $67.3 \mathrm{~mm}$. The samples were dried at room temperature, away from light, and humidity, and then the leaves are separated for extraction of essential oils with hydrodistillation using a Clevenger apparatus (Clevenger, 1928), obtained oils were treated with anhydrous sodium sulfate and stored at $+4^{\circ} \mathrm{C}$.

\subsection{GC analysis}

Chromatographic analyses of volatile compounds were carried out at the Research Laboratory of Fundamental Sciences at the University of Laghouat in Algeria, using a gas chromatograph GC-5400 equipped with a flame ionization detector (FID) and a fused silica capillary column of type DB-5 $(30 \mathrm{~m} \times 0.32 \mathrm{~mm}$, film thickness $=0.10 \mu \mathrm{m}$ ). The vector gas used is hydrogen with a flow rate of $1 \mathrm{~mL} / \mathrm{min}$. The temperature of the column is programmed at a rate of $5^{\circ} \mathrm{C} / \mathrm{min}$ from $50^{\circ} \mathrm{C}$ to $250^{\circ} \mathrm{C}$. The temperature of injector and detector was set at $250^{\circ} \mathrm{C}$ and $280^{\circ} \mathrm{C}$, respectively. Essential oil solutions are prepared by dissolving $10 \mu \mathrm{L}$ of each in $1 \mathrm{~mL}$ of pentane organic solvent. Linear retention indices of the constituents are based on a series of alkane
(C8-C20) analyzed under the same operating conditions as those of the samples.

\subsection{Soil analysis}

$\mathrm{pH}$ was measured with a $\mathrm{pH}$ meter in a water suspension, with a soil-to-water ratio of $1 / 2.5$. Electrical conductivity (EC) was determined by a conductivity meter at $25^{\circ} \mathrm{C}$ with a sol-tosolution ratio of $1 / 5$. Calcium carbonate $\left(\mathrm{CaCO}_{3}\right)$ content was determined by the volumetric method consisting of an acid treatment of the soil with hydrochloric acid $(\mathrm{HCl})$, followed by a titration of the excess of $\mathrm{HCl}$ with sodium hydroxide $(\mathrm{NaOH})$ in the presence of phenolphthalein that allows a change of the mixture color passing from transparent to pink. Total nitrogen determination was made by Kjeldahl method, potassium $\left(\mathrm{K}^{+}\right)$ by a flame spectrometer, and phosphorus $(\mathrm{P})$ by spectrometry. Soil texture of the samples was determined by Robinson's pipette based on the Stokes law.

\subsection{Species distribution modeling}

MaxEnt 3.4.1 was used to establish current and future distribution models of $R$. adpressum; it is known by its very good performance especially with small samples (Elith et al., 2006). The 99 points of presence make the samples of this analysis; the points were downloaded from Global Biodiversity Information Facility (GBIF) in addition to our own recorded observations. Climate data have been downloaded from WorldClim Version 2 (Hijmans et al., 2005) with a spatial resolution of $30 \mathrm{~s}$ ( $1 \mathrm{~km})$; these are monthly mean data of minimum, mean and maximum temperature, and precipitation from 1970 to 2000, of which a total of 19 WorlClim bioclimatic were used to predict the potential distribution of $R$. adpressum. The general parameters of model execution in threshold features are 10 replications of cross-validate, max iteration at 500, and logistic ASC output format. Climate projection for predicting the influence

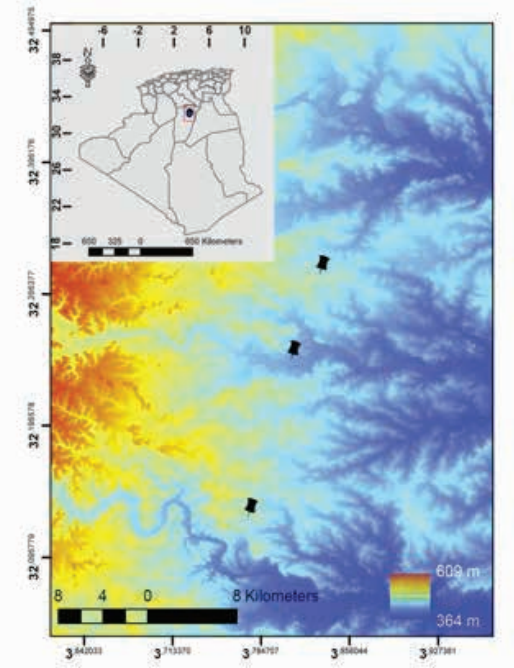

(a)

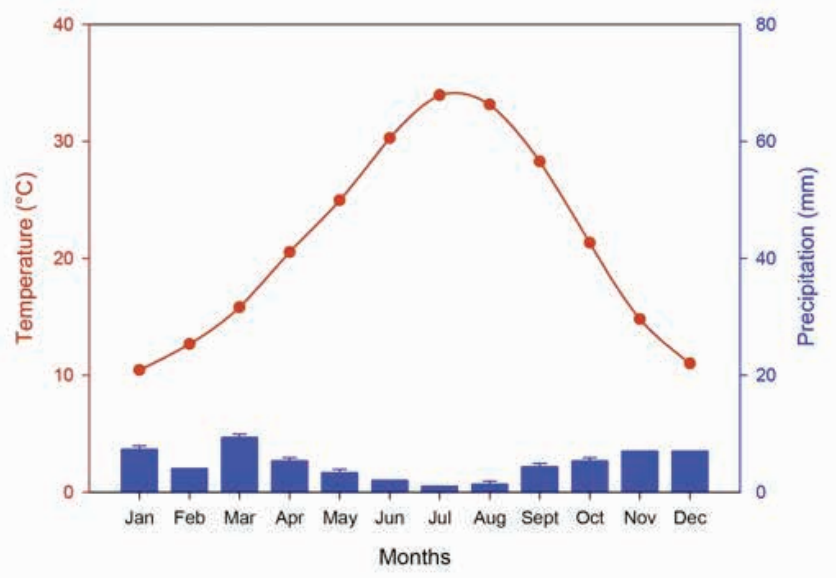

(b)

Figure 1: Presentation of R. adpressum sampling stations: (a) elevation map of study area where collection sites are represented by black pushpins and (b) ombrothermic diagram of the three sites. 
of climate changes under the four RCP scenarios $(2.6,4.5,6.0$, and 8.5) up to 2070 was based on GCSM data of 30-s resolution applying 10-percentile training presence threshold rule.

\subsection{Statistical analysis}

Statistical significance of effects and interactions of soil properties with chemical families of the total composition of essential oils was performed by factorial analysis with Minitab 17.3.1.

\section{RESULTS}

\subsection{Modeling the distribution of $\boldsymbol{R}$. adpressum}

In the obtained MaxEnt model, 89 presence records were used for training and 10,089 points were used to determine the Maxent distribution (background points and presence points) with training area under curve, $A \cup C=0.984$. In Figure 2, distribution model and favorable habitats for the genus Rhanterium extend from the west to the east of Algeria in an arid and hyperarid climatic zone (aridity index: between 0.03 and 0.19 ), this model is not specific for $R$. adpressum but also for the other two species, namely, Rhanterium suaveolens to the east, $R$. adpressum from the west to the center of this zone in a geographical extent started from southern Morocco and between these two typical species are habitats for hybrids such as Rhanterium intermedium, a comparison of morphological variations between these three species is part of the study of Wiklund (1986). A fluctuation in the temperature is more or less important from 1 month to another relative to the year (Bio3); the mean temperature of coldest quarter (Bio11) and the mean temperature of driest quarter (Bio9) are the bioclimatic variables that have the greatest contribution to determining the most favorable habitats for the distribution of these species (Fig. 3).
Future projections for the impact of climate change on the distribution of Rhanterium show that, for all scenarios, favorable habitats for this species will be changed (Fig. 2) and, therefore, these habitats will be very limited and may be rare as a result of significant drought trends in these areas resulting from global warming, leading to soil degradation and disruption of the hydrological cycle as climate simulations reveal an expansion of arid zones by $10 \%$ on the horizon of 2100 (Huang et al., 2016) and the warming can go up by $1.6^{\circ} \mathrm{C}$ until 2050 (Lioubimtseva, 2004).

\subsection{Soil chemical properties}

The average of chemical properties of nine soil samples from the three investigated sites is shown in Figure 4. Sand dominates physical composition of all samples (77-96\%) with low percentages of silt (3-24\%) and clay (0.3-8\%). A calcareous aspect has been characteristic for these samples with percentages between $35 \%$ and $45 \%, \mathrm{CaCO}_{3}$ has buffered the $\mathrm{pH}$ of soil around 8.2 and 8.7 , and in this type of soil, $\mathrm{pH}$ cannot be changed; alkalinity, therefore, decreases the permeability of the soil, and plants, in general, are facing nutrient absorption restrictions (Dagar, 2005; Jafari et al., 2018).

\subsection{Essential oils chemical composition}

Chromatographic analyses of 15 samples of $R$. adpressum essential oils distributed in 5 months from 3 sites allowed to show the variability in chemical composition of terpenes families (Fig. 5). The dominance of monoterpenes hydrocarbons family (77-90\%) in this composition is characterized by compounds with higher or lower percentages depending on month and site; $\alpha$-pinene (9-26.6\%), $\beta$-pinene (7-22\%), $\alpha$-terpinene (0.6-9\%), and limonene (1.1-15.9\%). Oxygenated monoterpenes (4.5-9.2\%), sesquiterpenes hydrocarbons (1.6-9.9\%),

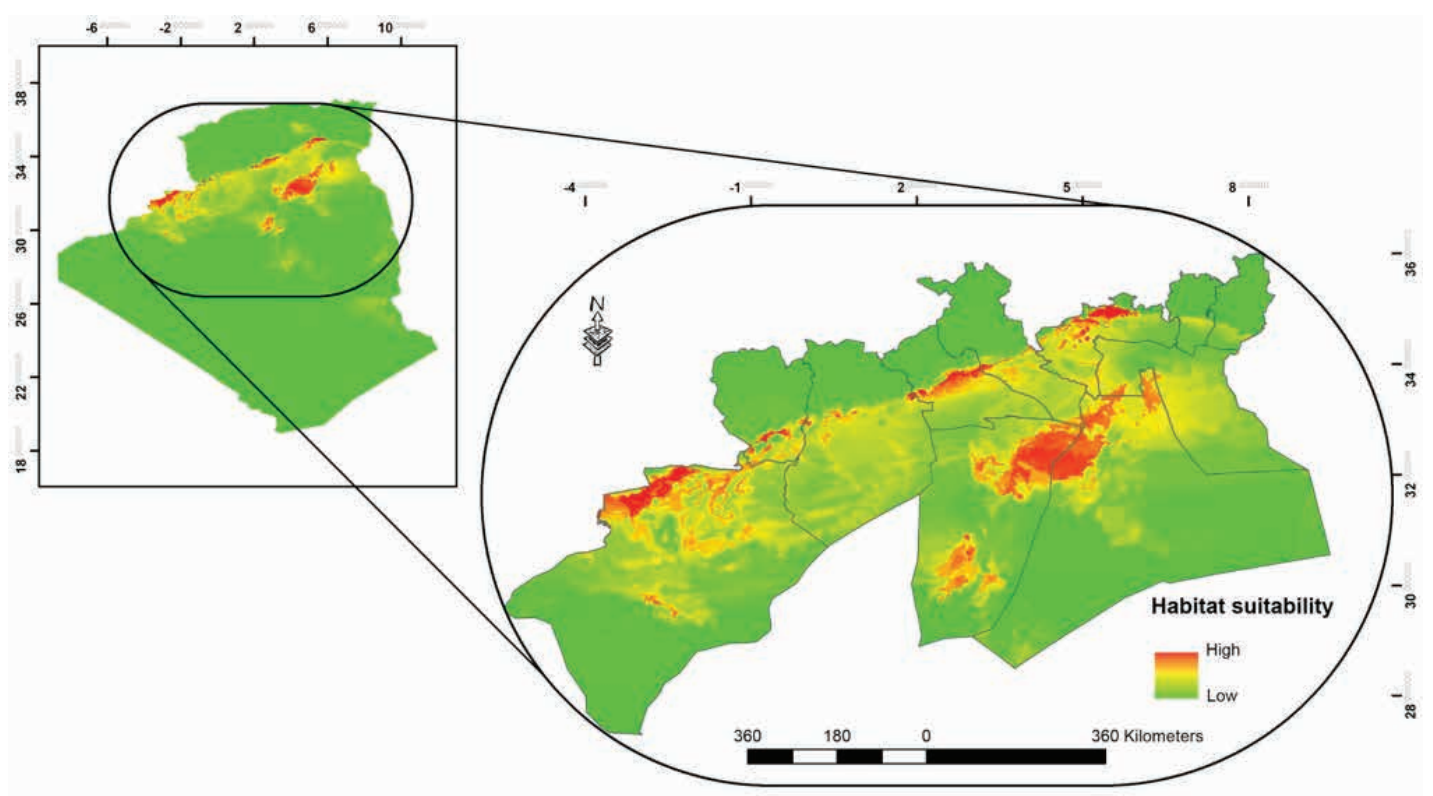

Figure 2: Presentation of distribution model based on the prediction of favorable habitats of the genus Rhanterium in Algeria 


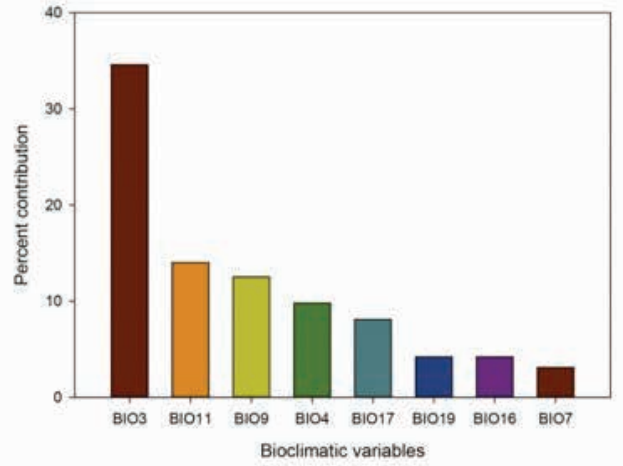

(a)

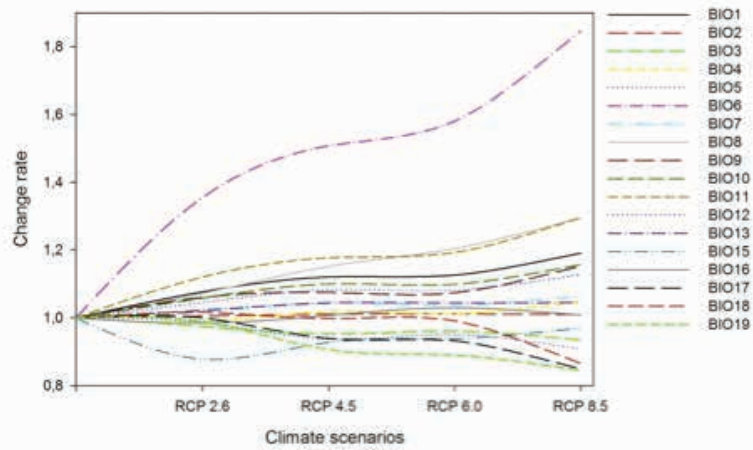

(b)

Figure 3: Bioclimatic variables, contribution, and variation in obtained models: (a) percent contribution of the first eight variables in the distribution model under current conditions and (b) change rate of these variables according to the four RCP scenarios.

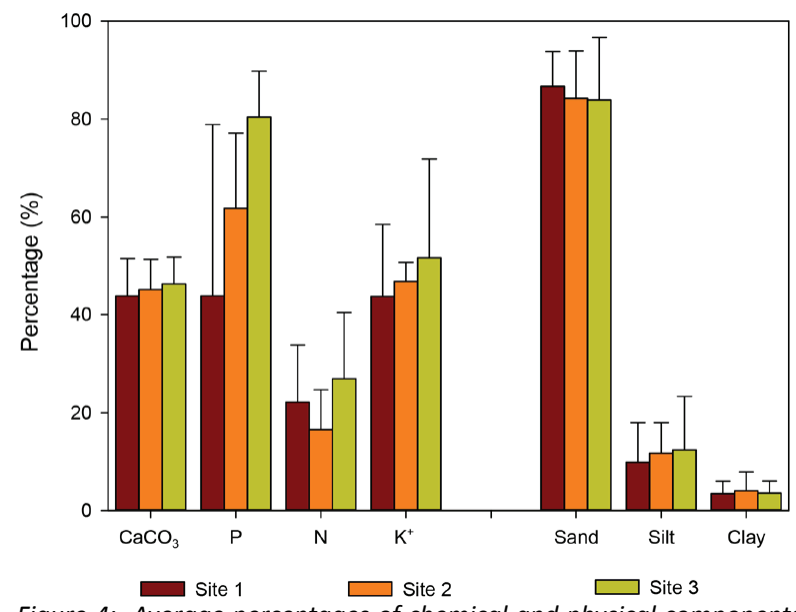

Figure 4: Average percentages of chemical and physical components of the analyzed soil samples.

and oxygenated sesquiterpenes (4.3-7.2\%) are terpenoids that have been weakly synthesized by the plant during this period of the year.

\section{DISCUSSION}

$R$. adpressum forms large clumps in dayas, river beds, sand dunes, and Hamadas in altitudes between 600 and 1200 m. It has been noticed that the temperature has increased in high zones, thus increasing the diurnal difference between minimum and maximum temperatures, which explains the elevationclimate change relationship and suggestions of studies that higher regions are warming up faster than others (Bandopadhyay, 2016). On the other hand, the flowering of $R$. adpressum was reported in 19th and 20th centuries between March and June (Battandier and Trabut, 1888; Wiklund, 1986), whereas today this period starts earlier in December and January until April and May under the effect of temperature and photoperiod showing the sensitivity of flowers to these factors (Craufurd and Wheeler, 2009). This shift of flowering has also been noticed in other species (Fitter and Fitter 2002), therefore,

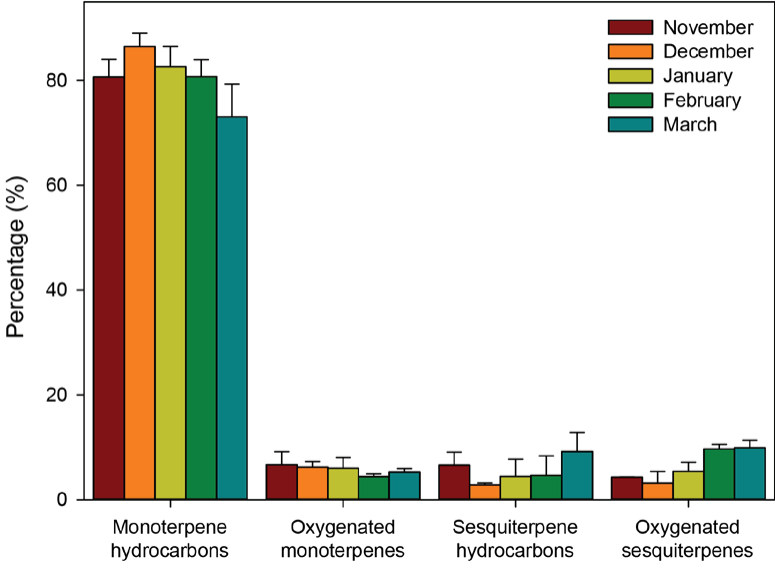

Figure 5: Average of chemical composition families of $R$. adpressum essential oils from three sites in a period of 6 months.

influencing other animals for which pollen and seeds are important resources, and by these great changes, the ecosystem structures will be disrupted (Visser and Holleman, 2001).

Other factors such as overgrazing, cultivation, and land grabbing may also affect the habitats of this species. On the basis of on a diachronic comparison (1989 and 2007) of $R$. suaveolens steppe in Tunisia, a regression by $52.7 \%$ of this steppe was noticed with a rate of decline of $1.28 \%$ (Attia et al., 2014). On this steppe, studies have investigated the impact of overgrazing and anthropogenic factor that caused by its degradation a scarcity of the vegetation cover, leading to desertification and disorganization of the physical states of soils (Novikoff, 1976; Jauffret and Lavorel, 2003).

The soil stoichiometry of $\mathrm{CaCO}_{3} / \mathrm{P}$ ratio available in arid and semiarid zones significantly influences plant growth and plant density; this relation inversely proportional with four communities of Artemisia ordosica was the objective of XueLai et al. (2012) study. Alkalinity noticed in the samples is interpreted by sodicity represented by an electrical conductivity (EC) between 0.2 and $1.8 \mathrm{dS} / \mathrm{m}$ at $20^{\circ} \mathrm{C}$; in this conductivity range, the total concentrations of salts are not high but the percentage of 
exchangeable sodium (PES) can be at levels harmful to plants (Jafari et al., 2018) and the chemistry of these soils will also be influenced by the levels of $\mathrm{CaCO}_{3}, \mathrm{~K}^{+}, \mathrm{P}, \mathrm{NO}_{3}{ }^{-}$, and $\mathrm{N}$. These minerals are crucial for the development of plants and can constitute, among others, $5-10 \%$ of biomass. Plants, on their part, play an important role in redistribution, transformation, chemical movement from/to light, atmosphere, and soil; the fact that plants can change their local environments (soil) especially in arid environments is a character of desert shrubs and steppe ecosystems, leading to the concept of "islands of fertility" (Jobbágy and Jackson, 2004; Waring et al., 2015; Schlesinger et al., 1996).

In a previous study, it was noticed that in terpenes families, in the composition of essential oils from $R$. adpressum extracted during a period of 3 months, April, May, and June which represent the terminal phase of vegetative cycle, there is a decrease in the percentage of monoterpenes hydrocarbons and a slight increase in the percentage of oxygenated monoterpenes with a nonsignificant variability in the total sesquiterpenes percentages. This is a remark noted in the two parts of the plant: leaves and flowers (Elhouiti et al., 2017). It was found that following the phenological cycle of $R$. adpressum, the total chemical composition of essential oils is mainly characterized by monoterpenes hydrocarbons but with remarkable temporal and spatial variations in elemental composition (Elhouiti et al., 2016, 2017).

Studies have proven the variation in content, quality, and composition of essential oils with the progression of plant phenology (Mirjalili et al., 2006; Chauhan et al., 2013), and in the same phenological stage, these characteristics are also varied according to altitude and the factors of microclimate (Alimohammadi et al., 2017; Lago et al., 2006). This variability may be a consequence of all these influences, but it also results from mechanisms of regulation of production of terpenes in response to different stresses, attacks of herbivores, and physical changes in habitat (Mann, 1987).

\subsection{Soil properties and essential oils chemical composition relationship}

Salinity and sodicity problems are widespread in arid and semiarid zones. In fact, halomorphous soils have been identified as saline, alkaline, sodium, saline-alkaline, or saline-sodium characterizing steppic and semi-desert lands (Dagar 2005). Sodicity and salinity exert chemical pressures by affecting seed germination, vegetative growth, and osmotic functioning (Singh et al., 2015). In this study, the statistical analysis of factorial design made it possible to show significantly positive $(\alpha=0.05)$ relations of EC, $\mathrm{P}$, and their association with the variation in monoterpenes (Coeffs: 357, 384.9, and 408.3) and sesquiterpenes (Coeffs: 86.5, 84.25, and 92.05) hydrocarbons. In contrast, a significant negative interaction among these variables and oxygenated monoterpenes $(-150.4,-153.9$, and -165.5$)$ and sesquiterpenes $(-293,-315.2$, and -334.7$)$ has been revealed.

Mineral nutrients and their effects on yield and composition of essential oils have been investigated by several studies. Prasad et al. (2006) investigated on the influence of sodicity on growth and yield of Geranium essential oil and reported that they increase with the increase in PSE of up to $16 \%$ and $7 \%$, respectively, and beyond a significant decrease was noticed. In another study, PSE concentrations remarkably affect the growth of Ocimum sanctum and the cation content at all tested levels 15.7, 35.6, and 54.6 (Singh et al., 2015). The addition of phosphorus increases cation content, vegetative characteristics of Lavandula $\times$ intermedia, and essential oil content at a tolerable level of $100 \mathrm{~kg} \mathrm{ha}^{-1}$ (Erbaş et al., 2017). The effect of N, P, and $\mathrm{K}$ doses on the growth and yield of essential oils of Mentha longifolia, Ocimum basilicum, and Matricaria chamomilla showed more or less tolerable responses of plants to these changes (Alsafar and Al-Hassan, 2009; Sharafzadeh et al., 2011; Emongor et al., 1990).

Showing effects-responses of these environmental factors on studied plants helps to explain the interactions governing phenological cycle, but it still remains in agricultural perspectives. In the wild, responses of plants in their niches differ from "inductive" aspect by an "adaptive" aspect, and, therefore, morphology and chemistry of these plants will be characteristic in a given biotope. In arid climates, plants use volatile compounds, often monoterpenes (Mann, 1987), a response due to adaptive behavior because, for limited nitrogen plants, for example, the metabolic cost to produce alkaloids is very expensive than producing terpenoids (Feeny, 1976) and these terpenoids can play important roles in communication, in attraction, and, through their mobility and diffusion in air and in soil, in defense (Yazaki et al., 2017).

Acknowledgements: The authors would like to thank Mr. Elhouiti BadrEddine, Mr. Elhouiti AbdelKader, and Pr. Gourine Nadhir for their help in the realization of this study.

Conflict of interest: The authors declare that they have no conflict of interest.

References

Alimohammadi, M., Yadegari, M., \& Shirmardi, H. A. (2017). Effect of elevation and phenological stages on essential oil composition of Stachys. Turkish Journal of Biochemistry, 42(6), 647-656.
Alsafar, M. S., \& Al-Hassan, Y. M. (2009). Effect of nitrogen and phosphorus fertilizers on growth and oil yield of indigenous mint (Mentha longifolia L.). Biotechnology, 8(3), 380-384. 
Attia, W., Tarhouni, M., \& Belgacem, A. O. (2014). Dynamique de la steppe à Rhanterium suaveolensen Tunisie présaharienne. Revue des Régions Arides. 34(2), 103-114.

Bandopadhyay, S. (2016). Does elevation impact local level climate change? An analysis based on fifteen years of daily diurnal data and time series forecasts. Pacific Science Review A: Natural Science and Engineering, 18(3), 241-253.

Battandier, J. A. \& Trabut, L. (1888). Flore de l'Algérie, Vol. 1, Alger : Jourdan $A$.

Buri, A., Cianfrani, C., Pinto-Figueroa, E., Yashiro, E., Spangenberg, J. E., Adatte, T. \& Pradervand, J. N. (2017). Soil factors improve predictions of plant species distribution in a mountain environment. Progress in Physical Geography, 41(6), 703-722.

Chauhan, N. K., Singh, S., Haider, S. Z., \& Lohani, H. (2013). Influence of phenological stages on yield and quality of oregano (Origanum vulgare I.) under the agroclimatic condition of doon valley (uttarakhand). Indian journal of pharmaceutical sciences, 75(4): 489-493.

Clevenger, J. F. (1928). Apparatus for the determination of volatile oil. The Journal of the American Pharmaceutical Association (1912), 17(4), 345-349.

Craufurd, P. Q., \& Wheeler, T. R. (2009). Climate change and the flowering time of annual crops. Journal of Experimental botany, 60(9), 2529-2539.

Dagar, J. C. (2005). Salinity research in India: An overview. Bulletin of the National Institute of Ecology, 15, 69-80.

El Houiti, F., Tahri, D., Seba, M., Ouinten, M., Gaydou, E. M., \& Yousfi, M. (2016). Inhibition of Fusarium oxysporum f. sp. albedinis by essential oils of flowers and stems of Rhanterium adpressum. PhOL PharmacologyOnLine, 3(22), 141-150.

Elhouiti, F., Tahri, D., Takhi, D., Ouinten, M., Barreau, C., Verdal-Bonnin, M. N., \& Yousfi, M. (2017). Variability of composition and effects of essential oils from Rhanterium adpressum Coss. \& Durieu against mycotoxinogenic Fusarium strains. Archives of microbiology, 199(10), 1345-1356.

Elith, J., Graham, C. H., Anderson, R. P., Dudík, M., Ferrier, S., Guisan, A., ... \& Li, J. (2006). Novel methods improve prediction of species' distributions from occurrence data. Ecography, 29(2), 129-151.

Emongor, V. E., Chweya, J. A., Keya, S. O., \& Munavu, R. M. (1990). Effect of nitrogen and phosphorus on the essential oil yield and quality of chamomile (Matricaria chamomilla L.) flowers. East African Agricultural and Forestry Journal, 55(4), 261-264.

Erbaş, S., Kucukyumuk, Z., Baydar, H., Erdal, I., \& Sanli, A. (2017). Effects of different phosphorus doses on nutrient concentrations as well as yield and quality characteristics of lavandin (Lavandulax intermedia Emeric ex Loisel. var. Super). Turkish Journal Of Field Crops, 22(1), 32-38.

Feeny, P. (1976). Plant apparency and chemical defense. In Biochemical interaction between plants and insects (pp. 1-40). Springer, Boston, MA.

Fitter, A. H., \& Fitter, R. S. R. (2002). Rapid changes in flowering time in British plants. Science, 296(5573), 1689-1691.

Golding, N., August, T. A., Lucas, T. C., Gavaghan, D. J., van Loon, E. E., \& Mclnerny, G. (2018). The zoon R package for reproducible and shareable species distribution modelling. Methods in Ecology and Evolution, 9(2), 260-268.

Guisan, A., Thuiller, W., \& Zimmermann, N. E. (2017). Habitat suitability and distribution models: with applications in R. Cambridge University Press.

Hageer, Y., Esperón-Rodríguez, M., Baumgartner, J. B., \& Beaumont, L. J. (2017). Climate, soil or both? Which variables are better predictors of the distributions of Australian shrub species?. Peer J, 5, e3446.

Hijmans, R. J., Cameron, S. E., Parra, J. L., Jones, P. G., \& Jarvis, A. (2005). Very high resolution interpolated climate surfaces for global land areas. International journal of climatology, 25(15), 19651978.

Huang, J., Ji, M., Xie, Y., Wang, S., He, Y., \& Ran, J. (2016). Global semiarid climate change over last 60 years. Climate Dynamics, 46(34), 1131-1150.

Jafari, M., Tavili, A., Panahi, F., Esfahan, E. Z., \& Ghorbani, M. (2018). Characteristics of Arid and Desert Ecosystems. In Reclamation of Arid Lands (pp. 21-91). Springer, Cham.

Jauffret, S., \& Lavorel, S. (2003). Are plant functional types relevant to describe degradation in arid, southern Tunisian steppes?. Journal of Vegetation Science, 14(3), 399-408.

Jobbágy, E. G., \& Jackson, R. B. (2004). The uplift of soil nutrients by plants: biogeochemical consequences across scales. Ecology, 85(9), 2380-2389.

Lago, J. H. G., Fávero, O. A., \& Romoff, P. (2006). Microclimatic factors and phenology influences in the chemical composition of the essential oils from Pittosporum undulatum Vent. leaves. Journal of the Brazilian Chemical Society, 17(7), 1334-1338.

Leroy, B., Meynard, C. N., Bellard, C., \& Courchamp, F. (2016). Virtual species, an $\mathrm{R}$ package to generate virtual species distributions. Ecography, 39(6), 599-607.

Lioubimtseva, E. (2004). Climate change in arid environments: revisiting the past to understand the future. Progress in Physical Geography, 28(4), 502-530.

Mann, J. (1987). Secondary metabolism. Oxford University Press.

Mirjalili, M. H., Salehi, P., Sonboli, A., \& Vala, M. M. (2006). Essential oil variation of Salvia officinalis aerial parts during its phenological cycle. Chemistry of Natural Compounds, 42(1), 19-23.

Novikoff, C. (1976). Traditional grazing practices and their adaptation to modern conditions in Tunisia and the Sahelian countries. Ecological Bulletins, 55-69.

Phillips, S. J., Anderson, R. P., \& Schapire, R. E. (2006). Maximum entropy modeling of species geographic distributions. Ecological modelling, 190(3-4), 231-259.

Prasad, A., Chattopadhyay, A., Chand, S., Naqvi, A. A., \& Yadav, A. (2006). Effect of Soil Sodicity on Growth, Yield, Essential Oil Composition, and Cation Accumulation in Rose-Scented Geranium. Communications in soil science and plant analysis, 37(1314), 1805-1817.

Schlesinger, W. H., Raikes, J. A., Hartley, A. E., \& Cross, A. F. (1996). On the Spatial Pattern of Soil Nutrients in Desert Ecosystems. Ecology, 77(2), 364-374.

Sharafzadeh, S., Esmaeili, M., \& Mohammadi, A. H. (2011). Interaction effects of nitrogen, phosphorus and potassium on growth, es- 
sential oil and total phenolic content of sweet basil. Advances in Environmental Biology, 5(6):1285-1290.

Singh, P. K., Verma, N. S., Pandey, N., \& Singh, P. (2015). Soil Sodicity Induced Changes in Aromatic Plants: Effects on Growth, Water Relation, Photosynthetic Pigments, Antioxidative Enzymes, Cations Concentration and Quality of Ocimum sanctum. Research Journal of Medicinal Plants, 9: 375, 394.

Visser, M. E., \& Holleman, L. J. (2001). Warmer springs disrupt the synchrony of oak and winter moth phenology. Proceedings of the Royal Society of London. Series B: Biological Sciences, 268(1464), 289-294.

Waring, B. G., Álvarez-Cansino, L., Barry, K. E., Becklund, K. K., Dale, S., Gei, M. G. \& Riggs, C. E. (2015). Pervasive and strong effects of plants on soil chemistry: a meta-analysis of individual plant 'Zinke' effects. Proceedings of the Royal Society B: Biological Sciences, 282(1812), 20151001.

Wiklund, A. (1986). The genus Rhanterium (Asteraceae: Inuleae). Botanical journal of the Linnean Society, 93(2), 231-246.

Yazaki, K., Arimura, G. I., \& Ohnishi, T. (2017). 'Hidden' terpenoids in plants: their biosynthesis, localization and ecological roles. Plant and Cell Physiology, 58(10):1615-1621.

Zhao, X., He, X., Xue, P., Zhang, N., Wu, W., Li, R., \& Zhao, H. (2012). Effects of soil stoichiometry of the $\mathrm{CaCO}$ /available phosphorus ratio on plant density in Artemisia ordosica communities. Chinese Science Bulletin, 57(5), 492-499. 